\title{
Synchronous and Asynchronous Transmitter Release at Nicotinic Synapses Are Differentially Regulated by Postsynaptic PSD-95 Proteins
}

\author{
Robert A. Neff III, William G. Conroy, Jeffrey D. Schoellerman, and Darwin K. Berg \\ Neurobiology Section, Division of Biological Sciences, University of California, San Diego, La Jolla, California 92093-0357
}

The rate and timing of information transfer at neuronal synapses are critical for determining synaptic efficacy and higher network function. Both synchronous and asynchronous neurotransmitter release shape the pattern of synaptic influences on a neuron. The PSD-95 family of postsynaptic scaffolding proteins, in addition to organizing postsynaptic components at glutamate synapses, acts transcellularly to regulate synchronous glutamate release. Here we show that PSD-95 family members at nicotinic synapses on chick ciliary ganglion neurons in culture execute multiple functions to enhance transmission. Together, endogenous PSD-95 and SAP102 in the postsynaptic cell appear to regulate transcellularly the synchronous release of transmitter from presynaptic terminals onto the neuron while stabilizing postsynaptic nicotinic receptor clusters under the release sites. Endogenous SAP97, in contrast, has no effect on receptor clusters but acts transcellularly from the postsynaptic cell through $\mathrm{N}$-cadherin to enhance asynchronous release. These separate and parallel regulatory pathways allow postsynaptic scaffold proteins to dictate the pattern of cholinergic input a neuron receives; they also require balancing of PSD-95 protein levels to avoid disruptive competition that can occur through common binding domains.

\section{Introduction}

A remarkable feature of neuronal synapses is their ability to communicate information with high fidelity in a temporally precise manner. Presynaptic action potentials cause two kinetically distinct modes of neurotransmitter release (Hagler and Goda, 2001). One is the near-simultaneous release of multiple quanta of neurotransmitter at synapses caused by a single presynaptic action potential that results in synchronous activation of postsynaptic receptors (Katz and Miledi, 1965; Borst and Sakmann, 1996). Elevated activity, however, can also cause presynaptic terminals to release neurotransmitter in a less coordinated and more delayed manner. This "asynchronous" release helps sustain excitatory or inhibitory tone during highfrequency synaptic transmission ( $\mathrm{Lu}$ and Trussell, 2000; Maximov and Sudhof, 2005; Iremonger and Bains, 2007; Daw et al., 2009). The ability to fine-tune such features of the release process not only extends the signaling range of synapses but also provides a mechanism for sustained bidirectional activity-dependent modification of synaptic efficacy (Lau and Bi, 2005; Wyart et al., 2005; Dan and Poo, 2006). Modifications of this type are thought to underlie a range of higher-order cognitive functions (Dan and Poo, 2006).

\section{Received 0ct. 5, 2009; accepted 0ct. 28, 2009}

Grant support was provided by the National Institutes of Health (NS012601 and NS035469) and the TobaccoRelated Disease Research Program (16RT-0167). We thank Xiao-Yun Wang for expert technical assistance. The synaptotagmin antibody was provided by the Developmental Studies Hybridoma Bank at the University of lowa, lowa City, and developed by the National Institute of Child Health and Human Development.

Correspondence should be addressed to Darwin K. Berg, Neurobiology Section, Division of Biology, 0357, University of California, San Diego, 9500 Gilman Drive, La Jolla, CA 92093-0357. E-mail: dberg@ucsd.edu.

D01:10.1523/JNEUROSCI.4951-09.2009

Copyright $\odot 2009$ Society for Neuroscience ～0270-6474/09/2915770-10\$15.00/0
The PSD-95 family of scaffold proteins plays a prominent role in coordinating and regulating synaptic function. In addition to being essential for postsynaptic receptor localization and downstream signaling, two of the family members, PSD-95 and SAP97, also act transsynaptically to regulate presynaptic function (ElHusseini et al., 2000; Sans et al., 2003; Kim and Sheng, 2004; Elias et al., 2006; Mauceri et al., 2007; Gardoni et al., 2009). Postsynaptic PSD-95 induces accumulation of presynaptic proteins that support synchronous glutamate release onto neurons by enhancing presynaptic $\mathrm{Ca}^{2+}$ sensitivity (Futai et al., 2007). Similarly, SAP97 in the postsynaptic cell acts in retrograde manner to recruit presynaptic release machinery and enhance presynaptic function at glutamate synapses (Regalado et al., 2006). How PSD-95 proteins coordinate these actions and whether asynchronous release is affected remain unanswered questions.

Nicotinic signaling is widespread throughout the vertebrate nervous system and is mediated by ligand-gated ion channels termed nicotinic acetylcholine receptors (nAChRs). The PSD-95 family organizes postsynaptic components at nicotinic synapses and helps stabilize nAChRs under presynaptic acetylcholine (ACh) release sites (Conroy et al., 2003; Parker et al., 2004; Temburni et al., 2004; McCann et al., 2008; Rosenberg et al., 2008). Which family members are responsible for receptor alignment and whether they influence ACh release is unknown.

We show here that PSD-95 and SAP102 together promote postsynaptic receptor expression and nicotinic synapse formation. In addition, they appear to act in a transcellular retrograde manner to enhance synchronous ACh release. In contrast, SAP97 has no effect on postsynaptic $\mathrm{nAChR}$ levels or distribution but acts transcellularly through $\mathrm{N}$-cadherin to promote selectively asynchronous ACh release. Overexpression of SAP97 can inter- 
fere with PSD-95 and SAP102 because of a common GK domain. The results demonstrate that PSD-95 family members have distinct capabilities in regulating the organization of presynaptic and postsynaptic components at nicotinic synapses and that their levels must be regulated to prevent mutual interference.

\section{Materials and Methods}

Cell cultures. Dissociated embryonic day 8 (E8) ciliary ganglion (CG) neurons were grown in culture for 7-8 d on glass coverslips coated with poly-D-lysine, fibronectin, and lysed fibroblasts as described previously (Nishi and Berg, 1981; Zhang et al., 1994). The neurons form nicotinic cholinergic synaptic connections with each other in culture under these conditions without the addition of preganglionic neurons (Chen et al., 2001; Conroy et al., 2003).

Transfections. Transient transfections were performed on HEK293 cells by calcium phosphate precipitation (Conroy and Berg, 1998). CG neurons were transfected at the time of plating as described previously (Conroy et al., 2003) using the transfection reagent Effectene (Qiagen, $0.25-0.5 \mu \mathrm{g}$ of DNA/well, 1:25 ratio of DNA/Effectene). The medium was replaced at $24 \mathrm{~h}$, and cultures were analyzed after 7-8 d. Typical transfection efficiencies were 1-2\%.

Truncated and chimeric PSD-95 family member constructs. Green fluorescent protein (GFP) fusion proteins for SAP102, SAP97, and PSD-93 (SAP102-GFP, SAP97-GFP, and PSD-93-GFP, respectively) were generated by PCR from cDNAs previously isolated from ciliary ganglia (Conroy et al., 2003) and positioned in frame at the $\mathrm{N}$ terminus of GFP in the vector pEGFP-N1 (Clontech). Truncated SAP97 and SAP102 constructs lacking the GK domain were prepared by PCR with the 3 ' primers ttaggatcccgatagttcacttcttgttgatgactg and tttggatcccgggcgtagtgaatttcttgccgtgtc, respectively, and subcloned in frame into pEGFP-N1.

RNA inhibition. A short hairpin RNA cassette (GenScript) was constructed using the following sequences for suppression of individual PSD-95 family members: PSD-93- caccagacattactcactctta, PSD-95gcgacagcttcgaggagatcta, SAP102 — agaaggatattcaggacaacaa, SAP97gcaaagcagttgaagcattaaa. The RNA cassettes were subcloned into the expression vector pRFPRNAic (ARK-Genomics, Roslin Institute) that uses a chick U6 promoter to drive expression of an RNA cassette with chick-specific microRNA sequences flanking a specific RNA interference (RNAi) target sequence and carries a red fluorescent protein (RFP) tag under control of a $\beta$-actin promoter to track transfection.

Specificity of the RNAi constructs was assessed by individually coexpressing them with PSD-93-GFP, SAP97-GFP, and SAP102-GFP in HEK293 cells. After 48 h, Triton X-100 lysates of the HEK293 cells were prepared and subjected to SDS-PAGE, electroblotted to nitrocellulose, and probed with anti-GFP monoclonal antibody (mAb) JL-8 (Clontech). Signals were visualized by enhanced chemiluminescence. Because fulllength chick PSD-95 was not available (and a mouse/chick hybrid PSD-95 proved lethal), we tested the specificity of the PSD-95 RNAi construct by transfecting it into E8 CG neuron and assessing effects on endogenous PDZ-containing proteins $7 \mathrm{~d}$ later. In this case, neurons were fixed with $2 \%$ paraformaldehyde, washed with PBS, and incubated overnight at $4^{\circ} \mathrm{C}$ in $\mathrm{PBS}(150 \mathrm{~mm} \mathrm{NaCl}, 10 \mathrm{~mm}$ sodium phosphate, $\mathrm{pH}$ 7.4) containing $5 \%$ normal donkey serum, $0.05 \%$ Triton X-100, and either an anti-PSD-95 mAb (1:500, clone K28/43) or a mAb that recognizes all four PSD-95 family members (1:500, clone K28/86.2; UC Davis/ NINDS/NIMH NeuroMab Facility Antibodies Inc.). The cells were then washed in PBS and incubated with FITC-conjugated donkey secondary antibody (1:250, Jackson ImmunoResearch Laboratories) for $1 \mathrm{~h}$ at room temperature (RT), rinsed, and imaged as described below.

Fluorescence microscopy. To label surface nAChRs, neurons were lightly fixed with $0.15 \%$ paraformaldehyde (PFA) for $20 \mathrm{~min}$ at RT, washed in Gray's balanced salt solution (GBSS), and incubated with the anti- $\alpha 1 / \alpha 3 / \alpha 5$ mAb 35 (1:500) (Conroy and Berg, 1998) for $30 \mathrm{~min}$ at RT. After washing in GBSS, cells were then fixed with $2 \%$ PFA in PBS, for 20 min at RT. To label intracellular antigens, cells were incubated with the anti-synaptotagmin mAb 48 (1:20; Developmental Studies Hybridoma Bank, University of Iowa Department of Biological Sciences) overnight at $4^{\circ} \mathrm{C}$ in PBS containing 5\% normal donkey serum and $0.05 \%$

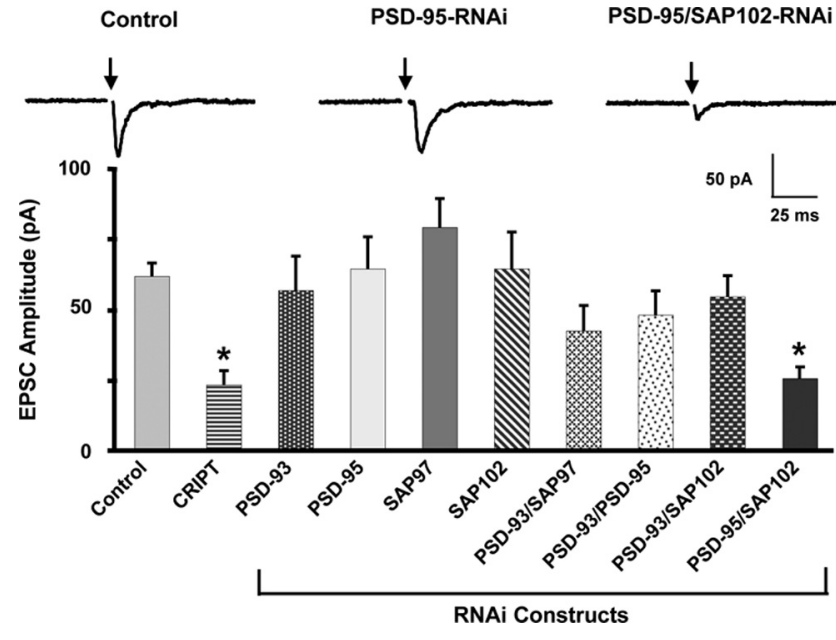

Figure 1. Simultaneous knockdown of PSD-95 and SAP102 reduces evoked EPSC amplitude in E8 CG neurons. Neurons transfected with the indicated constructs were patch clamped in the whole-cell configuration while stimulating presynaptic neurons with a bipolar extracellular stimulating electrode (arrows) to evoke maximal EPSCs. Dispersion of PDZ scaffolds with CRIPT reduced EPSC amplitude. RNAi knockdown of individual PSD-95 family members had no effect. Simultaneous knockdown of PSD-95 and SAP102, but not other combinations of PSD-95 family members, reduced EPSC amplitude. Values represent the mean \pm SEM with $n=8-23$ cultures per condition; $n=74$ for controls. ${ }^{*} p \leq 0.05$ by ANOVA with Dunnett's post hoc test.

Triton X-100. After washing in PBS, the cells were incubated with appropriate donkey Cy3-, Cy5-, or FITC-conjugated secondary antibody $1 \mathrm{~h}$ at RT (1:250; Jackson ImmunoResearch Laboratories), rinsed, and mounted on slides for imaging.

To label N-cadherin, cells were fixed with $2 \%$ PFA for 20 min at RT, rinsed, and incubated overnight at $4^{\circ} \mathrm{C}$ with an anti-N-cadherin $\mathrm{mAb}$ (1:500, clone GC-4). After washing in PBS, the cells were incubated with donkey FITC-conjugated secondary antibody $1 \mathrm{~h}$ at RT (1:250), rinsed, and mounted for imaging.

Cells were imaged and quantified as described previously (Conroy et al., 2007). Briefly, cells were viewed on a Zeiss Axiovert equipped with CCD camera and digital imaging with Slidebook software (Intelligent Imaging Innovations). Fields of view containing both a transfected and an untransfected neuron not contacting other cell bodies were randomly selected and imaged. Reconstructed images were generated from $z$-axis stacks of deconvolved $0.5 \mu \mathrm{m}$ optical sections. Control and experimental images were taken with the same exposure settings and displayed with the same dynamic range of pixel intensities for direct comparison.

For quantification of somatic receptor and synaptotagmin levels and alignment, three nonconsecutive focal planes were selected. Image intensities were thresholded manually, and the cell surface was masked for analysis by highlighting the perimeter of the cell surface with a drawing tool having a width of 12 pixels. Clusters/puncta within the masked area were defined as having at least 5 contiguous pixels with staining intensities at least twice background. Synaptotagmin puncta were counted as being aligned with $\mathrm{nAChR}$ clusters if they were within 4 pixels $(0.4 \mu \mathrm{m})$ of each other (Triana-Baltzer et al., 2008).

To quantify receptor and synaptotagmin levels and alignment, the most proximal $25 \mu \mathrm{m}$ segments of all neurites extending from a cell were masked in their entirety, thresholded, and analyzed as described above. Neurite data are all expressed as mean values per neurite.

Electrophysiology. Cultures containing CG neurons were immersed in artificial CSF (aCSF; $150 \mathrm{~mm} \mathrm{NaCl}_{2}, 3 \mathrm{~mm} \mathrm{KCl}, 2 \mathrm{~mm} \mathrm{CaCl}, 2 \mathrm{~mm} \mathrm{MgCl}_{2}$, $5 \mathrm{~mm}$ glucose, $10 \mathrm{~mm}$ HEPES) and placed in a recording chamber mounted on a Zeiss Axiovert. Patch pipettes (2.0-4.0 M $\Omega$ ) were visually guided to the surface of individual CG neurons. Patch pipettes contained $150 \mathrm{~mm} \mathrm{CsCl}, 4 \mathrm{~mm} \mathrm{MgCl} 2,2$ mм EGTA, $3 \mathrm{~mm} \mathrm{Mg-ATP}$, and $10 \mathrm{~mm}$ HEPES, pH 7.4. Voltage-clamp recordings were made with an Axopatch 200A, and Clampex 8.2 software (Molecular Devices). Data were acquired at $5 \mathrm{kHz}$ and filtered at $2 \mathrm{kHz}$. Pipette capacitance was canceled in all recordings. In experiments where nicotine was rapidly applied to 
neurons, whole-cell capacitance was neutralized, and series resistance was compensated by $80 \%$. All activity was recorded at $-70 \mathrm{mV}$. Transfected neurons were identified by the presence of GFP for overexpression constructs and RFP for RNAi constructs.

To evoke EPSCs, a bipolar extracellular stimulating electrode (Fredrick Hauer Company) was positioned with an untransfected presynaptic neuron between the two poles of the electrode. Square-wave current injections of $\leq 1 \mathrm{~mA}$ and $0.2-2.0 \mathrm{~ms}$ duration were applied at a frequency of $0.1 \mathrm{~Hz}$ to the soma and adjacent axon tracts of the presynaptic neuron with a pulse generator (Master-8) coupled through a stimulus isolator (Iso-flex; A.M.P.I.). Stimulus intensity was increased until maximum EPSC amplitude was achieved. For paired-pulse protocols, paired stimuli were applied to presynaptic neurons at frequencies ranging from 5 to $50 \mathrm{~Hz}$. Postsynaptic cells were discarded if they displayed stimulusevoked action potentials. The mean amplitude of 10 successfully evoked EPSCs was calculated using Clampfit 8.2 software (Molecular Devices).

To quantify asynchronous release, we substituted $3 \mathrm{mM} \mathrm{Sr}^{2+}$ for $\mathrm{Ca}^{2+}$ in the recording medium, thus enhancing the asynchronous mode of ACh release (Goda and Stevens, 1994). Presynaptic neurons were stimulated with a bipolar electrode as described above. To avoid any remaining synchronous release events in the analysis, we counted events that occurred 100-900 ms after stimulation. Asynchronous EPSCs were detected using automated mini detection software with a threshold-based spike detection algorithm and verified by visual inspection (Mini Analysis, Synaptosoft). For these experiments the amplitude threshold for mini detection was set at four times the SD of the mean background noise, $2.5 \mathrm{pA}$ (background noise range: $1.5-4.4 \mathrm{pA}$ ).

To record miniature EPSCs (mEPSCs), $1 \mu \mathrm{M}$ tetrodotoxin (TTX) was included in the recording medium. To record depolarizationinduced mEPSCs, the potassium concentration of the recording medium was raised to $10 \mathrm{~mm}$. Mini Analysis software was also used to detect the mEPSCs, with an amplitude threshold of four times the SD of the mean background noise level (low $\mathrm{K}^{+}: 1.4$ pA mean, $0.9-2.1$ pA range; high $\mathrm{K}^{+}: 2.2 \mathrm{pA}$ mean, $1.2-3.9 \mathrm{pA}$ range). All detected events were verified by visual inspection.

To assay the size of the readily releasable pool (RRP) of ACh, neurons patch-clamped in the presence of $1 \mu \mathrm{M}$ TTX were subjected to hyperosmotic shock (Rosenmund and Stevens, 1996). Briefly, a 4 s application of aCSF containing $0.5 \mathrm{~m}$ sucrose and $1 \mu \mathrm{M}$ TTX was ejected from a patch pipette positioned $30 \mu \mathrm{M}$ from the patched neuron using a Picospritzer (Parker Hannifin). To study the refill properties of the RRP, a second $4 \mathrm{~s}$ sucrose application was applied after a 1 min interval (Jüngling et al., 2006). Total charge was calculated by integrating the area of the response for $5 \mathrm{~s}$ after the application using Clampfit 8.2 software.

Whole-cell responses to nicotine were measured by rapidly applying nicotine $(20 \mu \mathrm{M})$ to neurons for $0.5 \mathrm{~s}$ using a large-bore applicator as described previously (Zhang et al., 1996). CG neurons in culture have only low levels of functional homopentameric $\alpha 7$-containing nAChRs ( $\alpha 7$-nAChRs), but to exclude any contribution from them to the wholecell nicotinic response, we routinely calculated the mean amplitude of the response for the last $100 \mathrm{~ms}$ of a $500 \mathrm{~ms}$ nicotine application. The rapid desensitization of $\alpha 7$-nAChRs largely constrains their contribution to

E
B
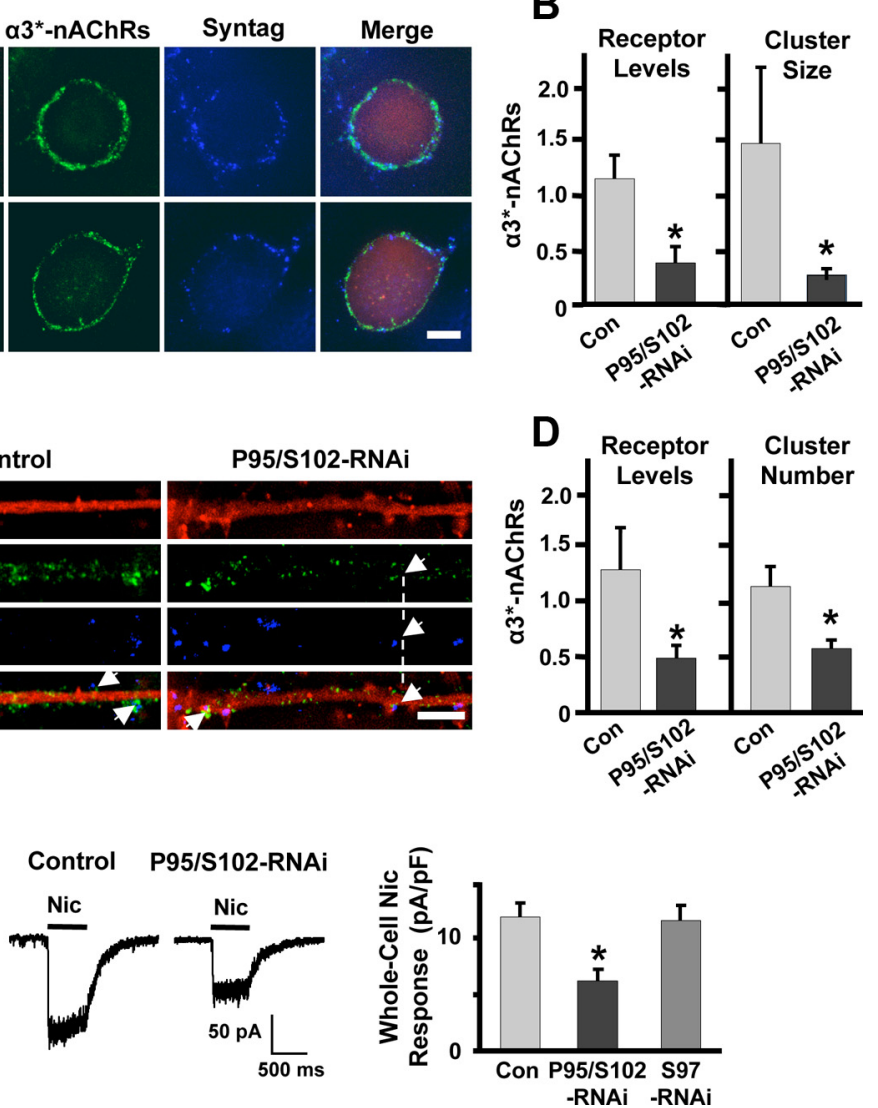

RNAi -RNAi

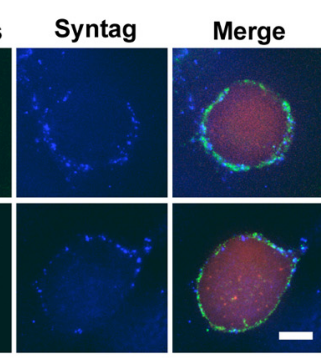

Figure 2. PSD-95/SAP102 knockdown alters $\alpha 3^{*}$-nAChR expression and synaptic alignment. $\boldsymbol{A}$, CG neurons transfected either

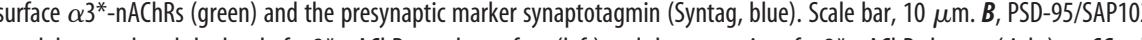
( mean size of $\alpha 3^{*}$-nAChR clusters (data not shown). $\boldsymbol{E}$, Left, Whole-cell responses to $20 \mu \mathrm{m}$ nicotine in a control neuron and a neuron transfected with PSD-95/SAP102-RNAi. Right, PSD-95/SAP102 knockdown decreased mean whole-cell responses to nicotine, whereas knockdown of SAP97 (S97-RNAi) had no effect. ${ }^{*} p \leq 0.05$ by unpaired Student's $t$ test (10 - 11 cultures/condition).

the first $50 \mathrm{~ms}$ of $20 \mu \mathrm{M}$ nicotine application (Zhang et al., 1994). The mean current amplitude of the heteropentameric $\alpha 3$-containing $\mathrm{AChR}$ $\left(\alpha 3^{*}\right.$-nAChR $)$ response for a neuron was determined by averaging three successive trials with nicotine ( $30 \mathrm{~s}$ intervals). Currents were analyzed using Clampfit 8.2 software.

Function blocking anti-N-cadherin $m A b$. Blocking with an anti-Ncadherin mAb was performed as described previously (Tang et al., 1998; Regalado et al., 2006). Briefly, coverslips were placed in wells containing $0.25 \mathrm{ml}$ of aCSF and either preimmune mouse IgG (Jackson ImmunoResearch Laboratories) or anti-N-cadherin $\mathrm{mAb}(1: 100)$. After a $2-3 \mathrm{~h}$ incubation, coverslips were transferred to a recording chamber and continually perfused with normal aCSF.

Statistics. Data are presented as the mean \pm SEM unless otherwise indicated. For each condition the mean represents the average of individual means obtained from cultures (individual coverslips) where 1-3 cell pairs were analyzed per culture; $n$ equals the number of cultures. Single comparisons were performed using paired Student's $t$ tests, or unpaired Student's $t$ tests without the assumption of homoscedasticity, as appropriate. Experiments with more than one experimental condition were performed using ANOVA with Dunnett's post hoc test for comparisons versus control, and Bonferroni's post hoc test for multiple comparisons. Differences in mEPSC amplitudes were determined using 
A

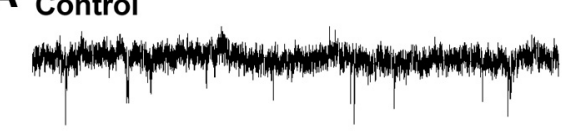

P95/S102-RNAi

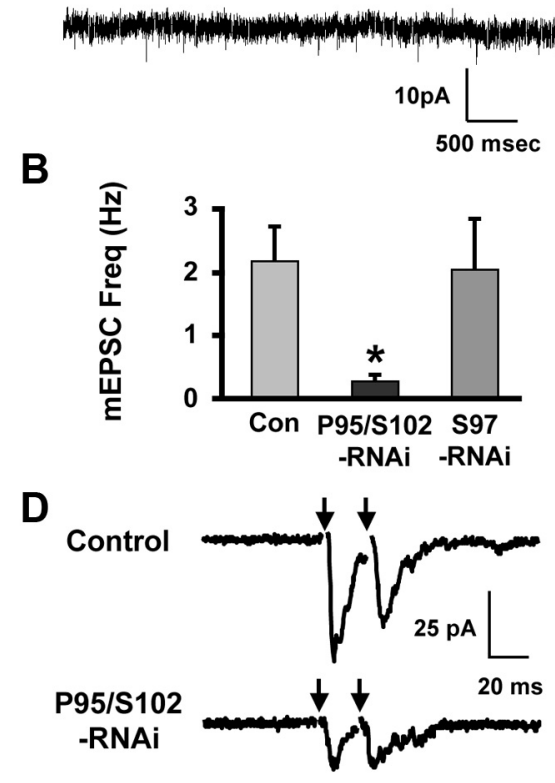

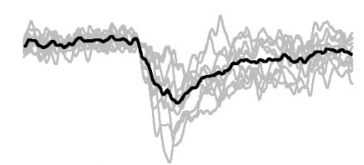

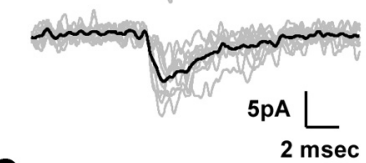

C

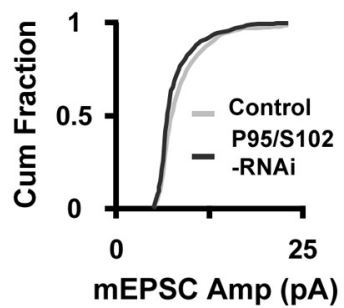

$\mathbf{E}$

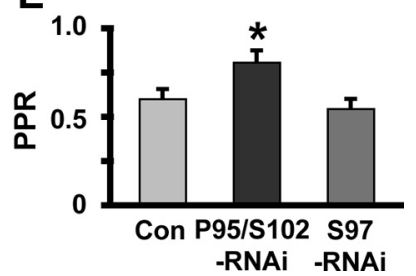

Figure 3. PSD-95/SAP102 knockdown diminishes spontaneous mEPSC frequency and PPD. $\boldsymbol{A}$, Left, Whole-cell patch-clamp recordings of mEPSCs in CG neurons in $1 \mu \mathrm{M}$ TTX. Right, Overlay of 10 consecutive mEPSCs (gray) and the resulting mean (black) from the cells yielding the recordings. $\boldsymbol{B}$, Knockdown of PSD-95 and SAP102 (P95/S102-RNAi), but not SAP97 (S97-RNAi), decreased mean mEPSC frequency in (G neurons ( ${ }^{*} p \leq 0.05$ by ANOVA with Dunnett's post hoc test). C, PSD-95/SAP102 knockdown also decreased mEPSC amplitude as seen in cumulative histograms (Cum Fraction; $p \leq 0.01$ by K-S test; $9-15$ cultures/condition). $D$, Paired responses in patch-clamped CG neurons exhibited PPD when presynaptic inputs were stimulated (arrows) at an interval of $20 \mathrm{~ms}$. $\boldsymbol{E}$, Neurons expressing PSD-95/SAP102-RNAi exhibited less PPD than did control neurons, whereas PPD was unchanged in neurons expressing SAP97-RNAi ( ${ }^{*} p \leq 0.05$ by unpaired Student's $t$ test; $11-15$ cultures/condition).

Kolmogorov-Smirnov tests on cumulative amplitude histograms. All data were subjected to Grubb's test for outliers. Statistics and data processing were performed using Prism (Graphpad), Excel (Microsoft), and Origin (OriginLab).

Materials. White leghorn chick embryos were obtained locally and maintained at $37^{\circ} \mathrm{C}$ in a humidified incubator. All reagents were purchased from Sigma unless otherwise indicated.

\section{Results}

PSD-95 family members required for evoked nicotinic signaling

Chick CG neurons express all four members of the PSD-95 family and receive cholinergic but not glutamatergic innervation in vivo (Dryer, 1994; Conroy et al., 2003). Disrupting the PDZ interactions of all PSD-95 family members with the dominant-negative construct CRIPT in culture reduces the number of functional nicotinic synapses CG neurons form with each other as evidenced by reduced numbers of EPSCs (Conroy et al., 2003). To determine which PSD-95 family members were responsible, we prepared RNAi constructs that selectively target individual family members and coexpress RFP. Specificity was demonstrated by showing that each construct reduced expression only of the cognate PSD-95 family member heterologously expressed in HEK293 cells and did not affect expression levels of other members (supplemental Fig. $1 A$, available at www.jneurosci.org as supplemental material). Because full-length chick PSD-95 was not available for these tests, we assessed the potency of the PSD-95 RNAi construct (PSD-95-RNAi) by transfecting CG neu- rons and then immunostaining for native PSD-95 with a specific antibody. A clear reduction was observed in PSD-95 staining (supplemental Fig. $1 B$, available at www.jneurosci.org as supplemental material). Immunostaining for the entire PSD-95 family showed that PSD-95RNAi expression had little overall effect, indicating it did not depress the other major contributors (supplemental Fig. 2, available at www.jneurosci.org as supplemental material). Transfecting with constructs encoding PSD-95-RNAi and SAP102-RNAi (PSD-95/SAP102-RNAi) did produce a significant decrease in overall staining for the PSD-95 family (supplemental Fig. 2, available at www.jneurosci. org as supplemental material).

To test for an effect on nicotinic input to the cells, we transfected CG neurons with RNAi constructs targeting PSD-95 family members and examined evoked EPSCs 7-8 d later. Under these conditions EPSCs are mediated primarily by $\alpha 3^{\star}$-nAChRs (Chen et al., 2001; Conroy et al., 2003). Because transfected cells represent only a small fraction $(<5 \%)$ of the total population, most of the synaptic input to a cell results from untransfected neighbors; the untransfected cells in the cultures are equivalent to controls, as noted previously (Conroy et al., 2003). Only the combination PSD-95/SAP102RNAi was effective at reducing the mean amplitude of the evoked EPSC, paralleling the effect of CRIPT overexpression (Fig. 1). None of the RNAi constructs alone, nor the other pairs tested, were effective. This suggested that PSD-95 and SAP102 both support nicotinic innervation. Moreover, they appeared to play complementary, if not overlapping, roles because both had to be knocked down before a deficit in nicotinic input could be detected.

cis versus trans effects of postsynaptic PSD-95/SAP102

We first tested for $c$ is effects involving postsynaptic $\alpha 3^{\star}$-nAChRs. CG neurons transfected with PSD-95/SAP102-RNAi were immunostained for $\alpha 3^{*}$-nAChRs on the cell surface (Fig. $2 A$ ). The cells had lower overall levels of $\alpha 3^{*}$-nAChRs on the soma and had smaller $\alpha 3^{*}$-nAChR clusters juxtaposed to synaptotagmincontaining boutons, compared to control cells expressing RFP (Fig. $2 B$ ). The method of staining would not have excluded presynaptic $\alpha 3^{\star}$-nAChRs, if they exist, but they are not expected to have made a significant contribution because both electron microscopic analysis of CG neurons in situ and immunofluorescent labeling of freshly dissociated CG neurons revealed prominent postsynaptic $\alpha 3^{*}$-nAChR clusters on the cells while presynaptic $\alpha 3^{\star}$-nAChRs were undetectable (Horch and Sargent, 1995; Shoop et al., 1999; Temburni et al., 2004; Rosenberg et al., 2008). No change was seen in the number of $\alpha 3^{*}$-nAChR clusters juxtaposed to synaptotagmin puncta abutting the soma (defined here as synaptic $\alpha 3^{\star}$-nAChR clusters; data not shown).

Because somatic recordings also include contributions from proximal neurites, we analyzed immunostains of neurite initial 
segments as well, and again found a reduction in the overall level of $\alpha 3^{*}$-nAChRs (Fig. 2C). In this case there was no change in $\alpha 3^{*}$-nAChR mean cluster size (data not shown), but there was a reduction in the number of synaptic $\alpha 3^{\star}$-nAChR clusters (Fig. 2D). Consistent with the decrement in overall $\alpha 3^{*}$-nAChR staining, wholecell recordings demonstrated that cells expressing PSD-95/SAP102-RNAi had smaller responses to nicotine than did cells expressing only control RFP (Fig. 2E). No change in whole-cell response was seen in cells expressing SAP97-RNAi. Thus synaptic $\alpha 3^{*}$-nAChR clusters were impacted differently on neurites versus cell bodies of PSD-95/SAP102-RNAi-expressing cells, suggesting that additional components influence receptor fate and that such components are not equally distributed between soma and proximal neurites. Both kinds of changes seen here with PSD-95/ SAP102-RNAi, however, would serve to diminish the evoked EPSC amplitude. Most influential would have been the percentage decrement in clusters on neurites because on control cells such clusters were at least three times as abundant as those on cell bodies $(25.2 \pm 3.3$ and $7.3 \pm 1.2$ clusters/cell for neurites and soma, respectively; $n=25$ cultures; $p \leq 0.0001$ ).

No change was seen in the number, size, or intensity of synaptotagmin-containing boutons contacting the soma of neurons expressing PSD-95/SAP102-RNAi (supplemental Fig. 3, available at www. jneurosci.org as supplemental material). Thus the substantial decrease in size of synaptic $\alpha 3^{*}$-nAChR clusters on the soma of such cells was not matched by a reduction in the size or number of presynaptic puncta contacting the clusters. Similarly, no significant change was seen in the number, size, or intensity of synaptotagmin puncta on neurites of PSD-95/SAP102RNAi-expressing cells (supplemental Fig. 3, available at www.jneurosci.org as supplemental material). While the variability in the synaptotagmin values would have obscured small changes, it seems clear that postsynaptic knockdown of PSD-95 and SAP102 did not produce major changes in the size or abundance of presynaptic release sites.

If the number of functional synapses is reduced by PSD-95/ SAP102-RNAi expression, one would expect to see a reduction in the frequency of spontaneously occurring mEPSCs. Further, if the size of postsynaptic $\alpha 3^{*}-\mathrm{nAChR}$ clusters is reduced, one might expect a reduction in mean mEPSC amplitude. Both of these were seen when mEPSCs were measured in the presence of TTX to block action potentials. PSD-95/SAP102-RNAi expression substantially reduced the frequency of mEPSCs (Fig. $3 A, B$ ). It also reduced, though less extensively, the amplitude of mEPSCs as revealed by cumulative amplitude histograms (Fig. 3C). SAP97-RNAi, tested as a negative control, had no effect on mEPSC frequency (Fig. $3 B$ ) or on amplitude (data not shown).

A

B
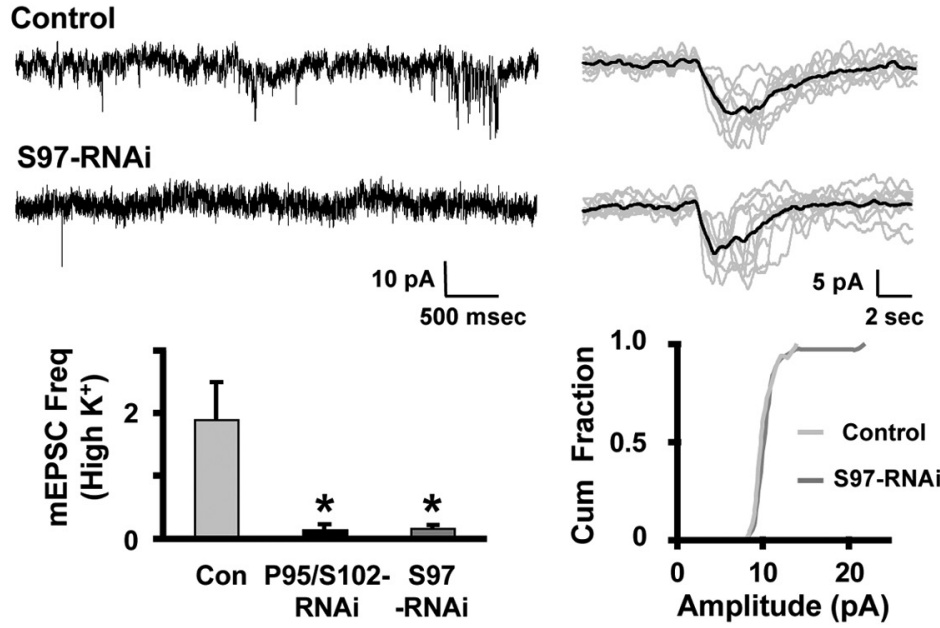

Con P95/S102- S97 Amplitude (pA)

Figure 4. SAP97 sustains nicotinic transmission during extended depolarizations and supports asynchronous ACh release. A, Top left, Traces showing mEPSCs recorded from CG neurons in the presence of $10 \mathrm{~mm} \mathrm{KCl}$ and $1 \mu \mathrm{m}$ TTX. Top right, 0verlay of 10 down of PSD-95/SAP102 or PSD-95 alone did not alter asynchronous release (values presented relative to controls in same cultures; ${ }^{*} p \leq 0.05$ by ANOVA with Dunnett's post hoc test; $4-19$ cultures/condition).

To test for a trans effect of PSD-95/SAP102-RNAi, we examined release probability. This was done by comparing the mean paired-pulse ratios (PPRs) of evoked EPSCs in control cells and cells transfected with PSD-95/SAP102-RNAi. When control cells were subjected to paired stimuli separated by a range of intervals (20-200 ms), they exhibited significant paired-pulse depression (PPD) at stimulation frequencies $>5 \mathrm{~Hz}$ ( $\leq 200 \mathrm{~ms}$ intervals). A $20 \mathrm{~ms}$ interval $(50 \mathrm{~Hz})$ was chosen for the paired pulses because this yielded the maximum PPD in control cells while still clearly separating the two evoked EPSCs in time (supplemental Fig. 4, available at www.jneurosci.org as supplemental material). Neurons transfected with PSD-95/SAP102-RNAi displayed a substantial decrement in PPD compared to control cells or cells transfected with SAP97-RNAi (Fig. $3 D, E$ ). The size of the RRP of transmitter in response to a sucrose challenge was not decreased by PSD-95/SAP102-RNAi expression (supplemental Fig. 5, available at www.jneurosci.org as supplemental material). The finding 
A

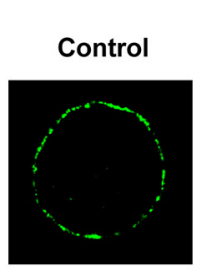

SAP97RNAi
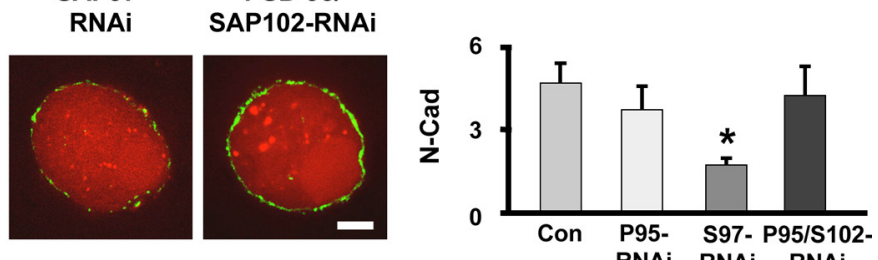

B
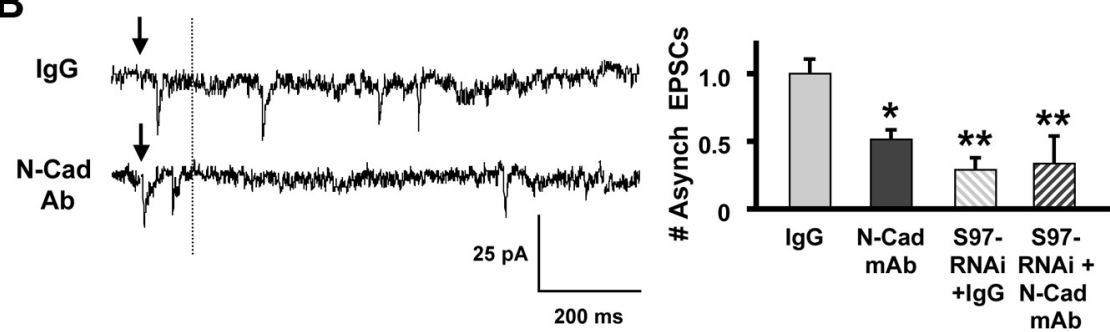

Figure 5. SAP97 knockdown impairs N-cadherin expression, a transmembrane protein important for asynchronous release. $\boldsymbol{A}$, Left, CG neurons expressing RNAi constructs targeting PSD-95 family members (red) were immunostained for N-cadherin (green). Right, N-Cadherin (N-Cad) levels were reduced by SAP97 (S97-RNAi) but not by PSD-95 (P95-RNAi) or PSD-95/SAP102 (P95/S102-RNAi) knockdown ( ${ }^{*} p \leq 0.05$ by ANOVA with Dunnett's post hoc test; $5-17$ cultures/condition). Scale bar, $5 \mu \mathrm{m}$. $\boldsymbol{B}$, Disruption of $\mathrm{N}$-cadherin interactions with a function blocking $\mathrm{mAb}$ (N-Cad $\mathrm{mAb}$ ) selectively impaired asynchronous release. Left, Traces showing asynchronous release (as in Fig. $4 B$ ) with cells treated with lgG (control) or N-Cad mAb. Right, Quantification showing that the $\mathrm{N}$-Cad mAb effect was equivalent to but not additive with the SAP-97-RNAi effect on asynchronous release $\left({ }^{*} p \leq\right.$ $0.05 ;{ }^{* *} p \leq 0.01$ by ANOVA with Dunnett's post hoc test; 6 cultures/condition).

that PSD-95/SAP102-RNAi reduced the amplitude of the evoked EPSCs (Fig. 1), while increasing substantially PPR (decreasing PPD), provides strong evidence that knockdown of PSD-95 and SAP102 in the postsynaptic neuron reduced the probability of transmitter release from presynaptic terminals contacting the cell. This would be a transcellular effect.

\section{Unique presynaptic effects of postsynaptic SAP97}

SAP97-RNAi had no effect on evoked EPSC amplitude, wholecell nicotinic response, mEPSC frequency, or PPD (Figs. 1-3), but did have an effect on one aspect of acetylcholine (ACh) release. Examining mEPSCs in elevated $\mathrm{KCl}$ showed that SAP97RNAi reduced mEPSC frequency under these conditions (Fig. $4 A$ ). Depolarization-induced mEPSC release is likely to be calcium mediated. Because SAP97 knockdown did not alter synchronous release (evoked EPSCs) (Fig. 1), we assayed asynchronous release, which also is calcium mediated and may contribute to mEPSCs under these conditions. To test whether SAP97 preferentially supports asynchronous ACh release, we examined evoked EPSCs in the presence of $3 \mathrm{mM} \mathrm{Sr}^{2+}$ (Goda and Stevens, 1994). Counting events that occurred 100-900 ms after stimulation demonstrated that SAP97-RNAi, but not PSD-95RNAi or PSD-95/SAP102-RNAi, significantly depressed asynchronous release (Fig. $4 \mathrm{~B}$ ).

$\mathrm{N}$-Cadherin may represent a mechanism by which SAP97 can transcellularly regulate presynaptic release in a retrograde manner. SAP97 in the postsynaptic neuron can act in part through $\mathrm{N}$-cadherin to regulate accumulation of release machinery at glutamatergic synapses on the cell (Regalado et al., 2006). N-Cadherin can also regulate voltage-gated calcium currents, a key determinant of transmitter release (Piccoli et al., 2004; Marrs et al., 2009). To test for an effect of SAP97 on N-cadherin, we transfected CG neurons with SAP97-RNAi and immunostained 7-8 d later. SAP97-RNAi substantially reduced surface N-cadherin levels while PSD-95-RNAi and PSD-95/SAP102-RNAi each had no effect (Fig. 5A). To test the relevance of $\mathrm{N}$-cadherin for asynchro- nous release, we applied a functionblocking anti-N-cadherin $\mathrm{mAb} 2-3 \mathrm{~h}$ before examining evoked release in $3 \mathrm{~mm}$ $\mathrm{Sr}^{2+}$ (replacing external $\mathrm{Ca}^{2+}$ ). The mAb produced a decrement in asynchronous release equivalent to that produced by SAP97 knockdown (Fig. 5B). Applying the $\mathrm{N}$-cadherin $\mathrm{mAb}$ to cells expressing SAP97-RNAi produced no further decrement (Fig. 5B). Neither the mAb nor SAP97-RNAi expression had any effect on synchronous release as reflected by evoked EPSC amplitude (data not shown). The results are consistent with SAP97 acting through $\mathrm{N}$-cadherin on the postsynaptic cell to exert a transcellular retrograde effect on asynchronous release.

\section{Overexpression of SAP97 and SAP102} constructs identifies a critical domain Overexpressing SAP97 in the neurons had an unexpected effect. Transfecting neurons with a SAP97 construct coupled to GFP for visualization (SAP97-GFP) produced changes similar in many respects to those caused by PSD-95/SAP102-RNAi rather than causing the opposite of SAP97-RNAi. SAP97-GFP reduced the mean amplitude of evoked EPSCs (Fig. 6A), reduced the whole-cell current induced by nicotine (Fig. $6 B$ ), and reduced PPD (increased PPR) (Fig. $6 C$ ). The results suggested that SAP97-GFP might function primarily as a dominant-negative for PSD-95 and SAP102. Heterologously expressed SAP97-GFP does distribute much more widely in CG neurons than does SAP102-GFP, consistent with the possibility that it binds to and redistributes components normally associated with the PSD-95/SAP102 complex (supplemental Fig. 6, available at www.jneurosci.org as supplemental material). Further support for a dominant-negative effect came from analysis of truncated constructs. Removing the GK domain of SAP97-GFP (SAP/GK-GFP) prevented it from reducing the evoked EPSC amplitude, changing the whole-cell response to nicotine, or altering the PPD (Fig. $6 A-C$ ), though the construct was expressed at levels comparable to other constructs. Overexpression of full-length SAP97 appears to exert a dominant-negative effect on pathways regulated by PSD-95 and SAP102, perhaps by competing for components that bind to a GK domain.

Additional evidence for the importance of a GK domain came from examining the effects of overexpressing SAP102 variants. Transfecting CG neurons with a full-length SAP102 construct (SAP102-GFP) in most respects achieved the opposite of PSD95/SAP102-RNAi, as might be expected. Thus, overexpressing SAP102 increased the mean amplitude of the evoked EPSCs by threefold (Fig. 7A), increased the number of $\alpha 3^{\star}$-nAChR clusters aligned under synaptotagmin-containing presynaptic contacts on neurites by fourfold (Fig. 7B), and increased the PPD (Fig. 7C). All of these actions were opposite in direction to those of PSD-95/SAP102-RNAi. Overexpression of SAP102 did not, however, increase the whole-cell response to nicotine (Fig. 7D) or the total amount of $\alpha 3^{\star}-n A C h R s$ on the cell surface as judged by immunostaining (data not shown), indicating that it could not by itself augment all elements vulnerable to PSD-95/SAP102-RNAi. 
Particularly revealing was the analysis of CG neurons transfected with a SAP102 construct lacking a GK domain (SAP102/ GK-GFP). It mimicked PSD-95/SAP102RNAi in behaving like a dominantnegative: it reduced the mean amplitude of evoked EPSCs (Fig. 7A), decreased the number of $\alpha 3^{*}$-nAChR clusters aligned under synaptotagmin puncta (Fig. $7 B$ ), decreased PPD (Fig. 7C), and reduced the whole-cell nicotinic response (Fig. 7D). The simplest explanation is that overexpressed SAP102/GK-GFP saturates key PSD-95/SAP102 binding sites, e.g., those involving PDZ domains, and therefore prevents endogenous PSD-95 and SAP102 from positioning needed GK-binding proteins at those sites. The results demonstrate the importance of the GK domain and indicate the vulnerability of PSD-95/ SAP102 actions to dominant-negative effects from components having a portion of their binding domains in common.

\section{Discussion}

The PSD-95 family of PDZ-containing proteins is vital for glutamatergic transmission. Here we show that three postsynaptic PSD-95 family members exert distinct but overlapping effects in coordinating nicotinic synapse formation and regulating nicotinic transmission. Preand postsynaptic mechanisms combine to achieve the common goal of reliable nicotinic input. PSD-95 and SAP102, which associate with $\alpha 3^{*}$-nAChRs (Conroy et al., 2003), together help maintain $\alpha 3^{*}$ $\mathrm{nAChR}$ clusters on the surface, align them under presynaptic release sites, and appear to regulate synchronous ACh release onto the receptors by a transcellular retrograde-acting mechanism. SAP97, in contrast, does not interact with $\alpha 3^{\star}$ nAChRs (Conroy et al., 2003) and does not affect $\alpha 3^{\star}$-nAChR cluster number, size, or position. Instead, it acts transcellularly, likely through $\mathrm{N}$-cadherin, to selectively support asynchronous ACh release. Overexpressing individual PSD-95 family members can be deleterious for nicotinic synapse formation. Together, the results demonstrate a multitiered regulation of nicotinic input by postsynaptic PSD-95 family members and indicate that the relative levels of individual family members must be controlled to optimize the pattern and strength of nicotinic input a neuron receives.

The ability of PSD-95/SAP102-RNAi to depress the amplitude of evoked EPSCs suggested both cis and trans effects of endogenous PSD-95 family members. The reduced $\alpha 3^{\star}$-nAChR cluster size and resulting reduction in mEPSC amplitude in PSD-95/ SAP102-RNAi transfected cells represents a cis effect. The decrease in probability of transmitter release, inferred from the reduced PPD, implies a trans effect. Fewer vesicles were released by the initial stimulus in this case, apparently leaving a higher fraction of the release sites occupied and able to discharge during the second stimulus of the pair, consistent with conventional PPD models (Dittman et al., 2000). A less likely alternative expla- nation is that postsynaptic changes in receptor mobility alters the postsynaptic response as recently reported for glutamate receptors (Heine et al., 2008; Frischknecht et al., 2009); whether $\alpha 3^{\star}$-nAChR mobility affects the EPSC is unknown. In support of a trans effect was also the finding that PSD-95/SAP102-RNAi decreased the mEPSC frequency without changing the RRP or number of synaptotagmin puncta abutting the cells. This too is consistent with a deficit in the release machinery at presynaptic sites contacting the cells.

Interestingly, PSD-95 and SAP102 at least partially compensate for each other in supporting nicotinic input. This follows from the finding that RNAi knockdown of either one alone proved insufficient to reduce evoked EPSCs. The two proteins clearly have overlapping capabilities. Compensatory upregulation may also occur, as seen for SAP102 and PSD-95 at glutamate synapses on rat hippocampal neurons (Elias et al., 2006).

SAP97-RNAi did not influence $\alpha 3^{*}$-nAChR trafficking to or distribution on the surface, in contrast to its effects on AMPA receptors (Rumbaugh et al., 2003; Nakagawa et al., 2004; Waites et al., 2009); nor did it alter synchronous ACh release. Surprisingly, it did exert a transcellular effect at nicotinic synapses to regulate asynchronous release of transmitter. This was indicated by the ability of SAP97-RNAi to depress mEPSC frequency elicited by elevated $\mathrm{KCl}$ concentrations while having no effect on 

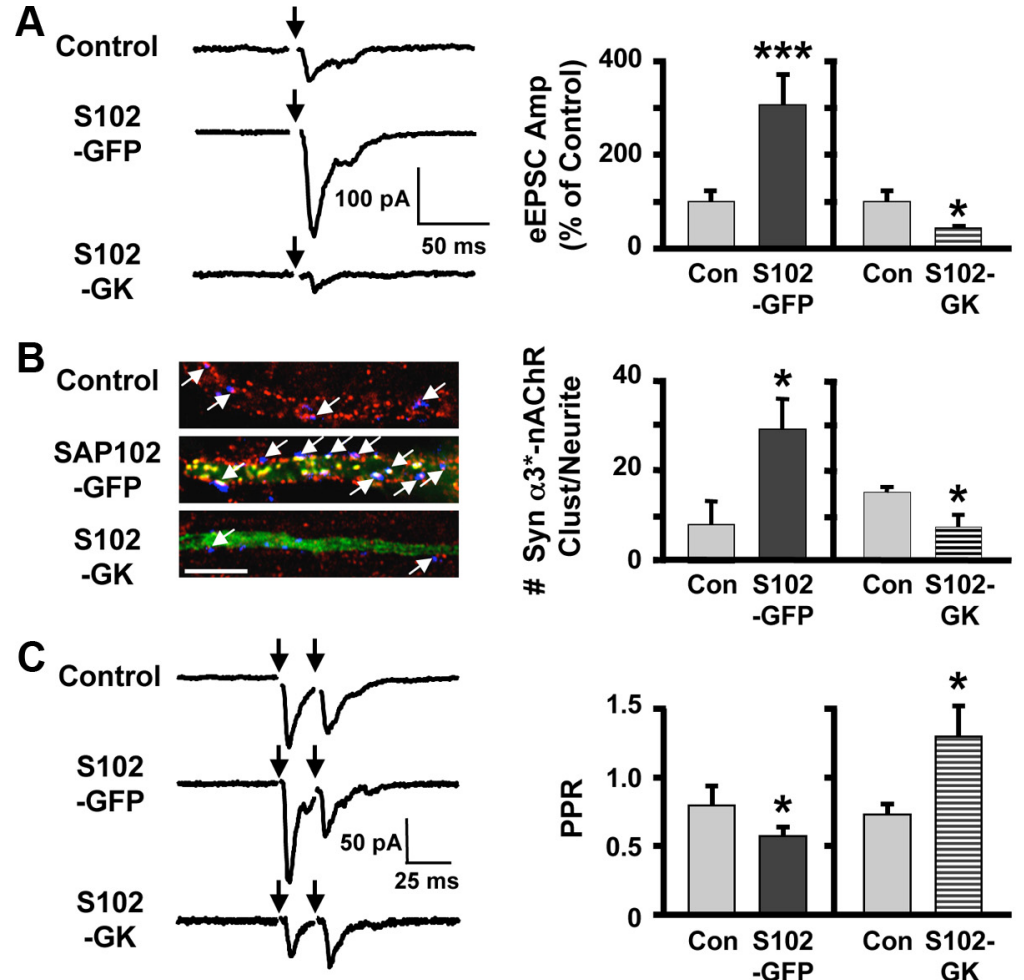

D
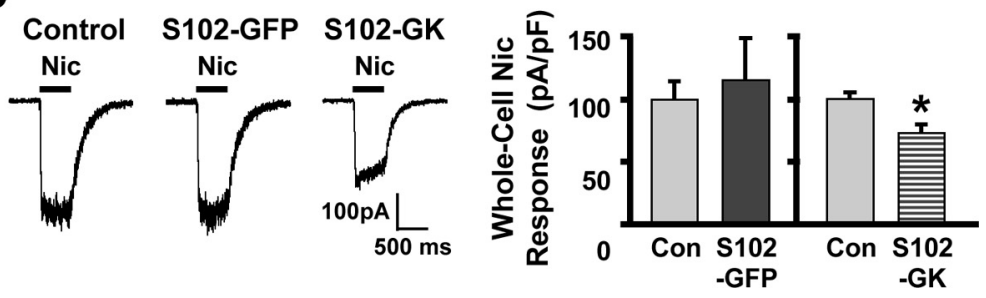

Figure 7. SAP102 requires a GK domain to enhance nicotinic synaptic input. $A$, Left, Evoked EPSCs. Right, SAP102-GFP (S102GFP) increased the mean evoked EPSC amplitude while SAP102/GK-GFP (S102-GK) reduced it (6-9 cultures/condition). B, Left, Proximal neurites of transfected neurons (green) immunostained for surface $\alpha 3^{*}$-nAChRs (red) and the presynaptic marker synaptotagmin (blue). Arrows indicate examples of receptor/synaptotagmin alignment. Right, SAP102-GFP expression increased the number of $\alpha 3^{*}$-nAChR clusters aligned with presynaptic specializations (Syn $\alpha 3^{*}$-nAChR Clust); SAP102/GK-GFP decreased it (4 cultures/condition). C, Left, Responses to paired stimuli. Right, SAP102-GFP increased PPD (decreased PPR) while SAP102/GKGFP decreased PPD (increased PPR; 7 cultures/condition). D, Left, Whole-cell responses to nicotine. Right, SAP102-GFP did not alter whole-cell responses to nicotine (5 cultures/condition), but SAP102/GK-GFP decreased it (6 cultures/condition). ${ }^{*} p \leq 0.05$; ${ }^{* * *} p \leq 0.001$ by unpaired Student's $t$ test.

either evoked EPSC amplitude or spontaneous mEPSC frequency in the absence of elevated $\mathrm{KCl}$. Confirmation was provided by direct measurement of evoked asynchronous release in the presence of $\mathrm{Sr}^{2+}$. Together, the results indicate that members of the PSD-95 family independently regulate synchronous and asynchronous transmitter release at nicotinic synapses.

Separate regulation of synchronous and asynchronous transmitter release was unexpected. The preponderance of evidence suggests that synchronous and asynchronous release access the same pool of synaptic vesicles but are mediated by different presynaptic calcium sensors (Goda and Stevens, 1994; Sun et al., 2007). Synchronous release dominates at low-frequency stimulation, coordinating vesicle release from multiple sites for additive effect with short latency. Asynchronous release can become prominent at high-frequency stimulation, extending the signaling range of the synapse (Lu and Trussell, 2000; Hagler and Goda, 2001; Hefft and Jonas, 2005; Iremonger and Bains, 2007). In principle, asynchronous release can be more broadly distributed than synchronous release because it does not require close proximity to voltage-gated calcium channels (Iremonger and Bains, 2007; Sun et al., 2007). Conceivably the two kinds of release may, in some cases, occupy different spatial domains. Chick ciliary neurons in vivo receive normal synaptic input via $\alpha 3^{*}$-nAChRs at postsynaptic densities and ectopic transmission via both $\alpha 3^{*}$ - and $\alpha 7$-nAChRs outside postsynaptic densities on somatic spines (Shoop et al., 2002; Coggan et al., 2005; Sargent, 2009). If the two spatially distinct kinds of release employ different calcium sensors (Daw et al., 2009), presynaptic firing frequency could determine the receptor subpopulation activated and therefore the downstream signaling pathways.

SAP97 and PSD-95 employ distinct retrograde signaling pathways at glutamate synapses. PSD-95 binds neuroligin, and postsynaptic neuroligin can interact with presynaptic $\beta$-neurexin to align presynaptic release sites over postsynaptic glutamate receptors (Irie et al., 1997; Scheiffele et al., 2000; Craig and Kang, 2007). PSD-95/neuroligin interactions also mediate transsynaptic regulation of transmitter release at glutamate synapses (Futai et al., 2007). CG neurons express a variety of neuroligins and neurexins (Ross and Conroy, 2008) and neuroligin-neurexin interactions promote nicotinic synapse formation between the neurons in culture (Conroy et al., 2007). Accordingly, neuroligin-neurexin offers a candidate transsynaptic bridge for postsynaptic PSD-95/SAP102 regulation of presynaptic events at nicotinic synapses, including synchronous release of ACh. Notably, PSD-95 also binds APC via a PDZ domain (Shimomura et al., 2007), and APC helps organize a postsynaptic complex in CG neurons that promotes nicotinic synapse formation (Temburni et al., 2004; Rosenberg et al., 2008). The APC complex may provide a second pathway for mobilizing neuroligin-neurexin transsynaptic effects.

SAP97, in contrast, is likely to act through N-cadherin to influence nicotinic synaptic function. $\mathrm{N}$-Cadherin is found at many synapses and has been widely documented to participate in glutamate synapse formation (Brusés, 2006). Postsynaptic SAP97 can use an N-cadherin link to influence presynaptic development at glutamate synapses (Regalado et al., 2006), and N-cadherin can self-associate to regulate voltage-gated calcium channels (Piccoli et al., 2004; Marrs et al., 2009). Results presented here indicate that CG neurons express $\mathrm{N}$-cadherin and that knockdown of SAP97, but not PSD-95/SAP102, reduced N-cadherin levels. Moreover, a function-blocking anti-N-cadherin $\mathrm{mAb}$ replicated the effects of SAP97-RNAi on asynchronous release, without affecting synchronous release. Combining the mAb with SAP97RNAi transfection produced no further reduction, consistent with a shared pathway or target. The results suggest that SAP 97 uses $\mathrm{N}$-cadherin as a transcellular bridge to exert effects on asyn- 
chronous release while a neuroligin-neurexin bridge is likely to mediate PSD-95/SAP102 regulation of synchronous release.

Overexpression of SAP97 and SAP102 constructs revealed the potential for cross talk between PSD-95 family members. While SAP102 overexpression yielded, for the most part, the opposite effects of PSD-95/SAP102 knockdown, SAP97 overexpression unexpectedly produced results similar to PSD-95/SAP102-RNAi rather than the opposite of SAP97 knockdown. This is consistent with a dominant-negative effect, and required the GK domain of SAP97. Further evidence for the importance of the GK domain came from SAP102 constructs where deletion of GK converted the truncated SAP102 sequence into a dominant-negative. This is perhaps surprising, given that PSD-95 can bind directly to neuroligin via a PDZ domain (Irie et al., 1997). Apparently such interactions are not alone sufficient to enhance nicotinic transmission and instead also require functional GKs. The GK domain interacts with numerous components (Feng and Zhang, 2009), and through GKAP and Shank, can tether Homer and regulators of F-actin (Kim et al., 1997; Naisbitt et al., 1999; Tu et al., 1999; Kim and Sheng, 2004). Both GKAP and Homer colocalize with PSD-95 in CG neurons (W. G. Conroy, unpublished results). An excess of GK domains provided by overexpression of a protein with inappropriate PDZ domains could misdirect associated proteins and their linked partners. Overexpressed SAP97-GFP did display a very different distribution in CG neurons from that of overexpressed SAP102-GFP. The results indicate that the neuron must tightly regulate the relative levels of individual PSD-95 family members for optimal outcomes.

CG neurons were used here because they readily form nicotinic cholinergic synapses in culture, express all four members of the PSD-95 family, and do not have glutamatergic innervation which could complicate interpretation of PDZ-protein manipulations. The results may have broad relevance, however, because nicotinic receptors are widely distributed throughout the CNS where they can serve both presynaptic and postsynaptic functions, generate fast EPSCs, and localize in part with PSD-95 (McGehee et al., 1995; Gray et al., 1996; Frazier et al., 1998; Hefft et al., 1999; Nong et al., 1999; Ji and Dani, 2000; Alkondon and Albuquerque, 2001; Fabian-Fine et al., 2001; Hatton and Yang, 2002; Levy and Aoki, 2002; Le Magueresse et al., 2006; Farías et al., 2007). The regulatory mechanisms that PSD-95 family members exert on nicotinic input to CG neurons may also extend to a variety of glutamate synapses in the CNS because the same combination of PSD-95 family members is coexpressed in many cases and because glutamatergic synapses can display both synchronous and asynchronous release. How common these regulatory mechanisms are at CNS synapses will be an important question for the future.

\section{References}

Alkondon M, Albuquerque EX (2001) Nicotinic acetylcholine receptor alpha7 and alpha4beta2 subtypes differentially control GABAergic input to CA1 neurons in rat hippocampus. J Neurophysiol 86:3043-3055.

Borst JG, Sakmann B (1996) Calcium influx and transmitter release in a fast CNS synapse. Nature 383:431-434.

Brusés JL (2006) N-Cadherin signaling in synapse formation and neuronal physiology. Mol Neurobiol 33:237-252.

Chen M, Pugh PC, Margiotta JF (2001) Nicotinic synapses formed between chick ciliary ganglion neurons in culture resemble those present on the neurons in vivo. J Neurobiol 47:265-279.

Coggan JS, Bartol TM, Esquenazi E, Stiles JR, Lamont S, Martone ME, Berg DK, Ellisman MH, Sejnowski TJ (2005) Evidence for ectopic neurotransmission at a neuronal synapse. Science 309:446-451.

Conroy WG, Berg DK (1998) Nicotinic receptor subtypes in the developing chick brain: appearance of a species containing the alpha4, beta2, and alpha5 gene products. Mol Pharmacol 53:392-401.

Conroy WG, Liu Z, Nai Q, Coggan JS, Berg DK (2003) PDZ-containing proteins provide a functional postsynaptic scaffold for nicotinic receptors in neurons. Neuron 38:759-771.

Conroy WG, Nai Q, Ross B, Naughton G, Berg DK (2007) Postsynaptic neuroligin enhances presynaptic inputs at neuronal nicotinic synapses. Dev Biol 307:79-91.

Craig AM, Kang Y (2007) Neurexin-neuroligin signaling in synapse development. Curr Opin Neurobiol 17:43-52.

Dan Y, Poo MM (2006) Spike timing-dependent plasticity: from synapse to perception. Physiol Rev 86:1033-1048.

Daw MI, Tricoire L, Erdelyi F, Szabo G, McBain CJ (2009) Asynchronous transmitter release from cholecystokinin-containing inhibitory interneurons is widespread and target-cell independent. J Neurosci 29:1111211122.

Dittman JS, Kreitzer AC, Regehr WG (2000) Interplay between facilitation, depression, and residual calcium at three presynaptic terminals. J Neurosci 20: $1374-1385$.

Dryer SE (1994) Functional development of the parasympathetic neurons of the avian ciliary ganglion: a classic model system for the study of neuronal differentiation and development. Prog Neurobiol 43:281-322.

El-Husseini AE, Schnell E, Chetkovich DM, Nicoll RA, Bredt DS (2000) PSD-95 involvement in maturation of excitatory synapses. Science 290:1364-1368.

Elias GM, Funke L, Stein V, Grant SG, Bredt DS, Nicoll RA (2006) Synapsespecific and developmentally regulated targeting of AMPA receptors by a family of MAGUK scaffolding proteins. Neuron 52:307-320.

Fabian-Fine R, Skehel P, Errington ML, Davies HA, Sher E, Stewart MG, Fine A (2001) Ultrastructural distribution of the $\alpha 7$ nicotinic acetylcholine receptor subunit in rat hippocampus. J Neurosci 21:7993-8003.

Farías GG, Vallés AS, Colombres M, Godoy JA, Toledo EM, Lukas RJ, Barrantes FJ, Inestrosa NC (2007) Wnt-7a induces presynaptic colocalization of $\alpha 7$-nicotinic acetylcholine receptors and adenomatous polyposis coli in hippocampal neurons. J Neurosci 27:5313-5325.

Feng W, Zhang M (2009) Organization and dynamics of PDZ-domainrelated supramodules in the postsynaptic density. Nat Rev Neurosci 10:87-99.

Frazier CJ, Buhler AV, Weiner JL, Dunwiddie TV (1998) Synaptic potentials mediated via $\alpha$-bungarotoxin-sensitive nicotinic acetylcholine receptors in rat hippocampal interneurons. J Neurosci 18:8228-8235.

Frischknecht R, Heine M, Perrais D, Seidenbecher CI, Choquet D, Gundelfinger ED (2009) Brain extracellular matrix affects AMPA receptor lateral mobility and short-term synaptic plasticity. Nat Neurosci 12:897-904.

Futai K, Kim MJ, Hashikawa T, Scheiffele P, Sheng M, Hayashi Y (2007) Retrograde modulation of presynaptic release probability through signaling mediated by PSD-95-neuroligin. Nat Neurosci 10:186-195.

Gardoni F, Marcello E, Di Luca M (2009) Postsynaptic density-membrane associated guanylate kinase proteins (PSD-MAGUKs) and their role in CNS disorders. Neuroscience 158:324-333.

Goda Y, Stevens CF (1994) Two components of transmitter release at a central synapse. Proc Natl Acad Sci U S A 91:12942-12946.

Gray R, Rajan AS, Radcliffe KA, Yakehiro M, Dani JA (1996) Hippocampal synaptic transmission enhanced by low concentrations of nicotine. Nature 383:713-716.

Hagler DJ Jr, Goda Y (2001) Properties of synchronous and asynchronous release during pulse train depression in cultured hippocampal neurons. J Neurophysiol 85:2324-2334.

Hatton GI, Yang QZ (2002) Synaptic potentials mediated by $\alpha 7$ nicotinic acetylcholine receptors in supraoptic nucleus. J Neurosci 22:29-37.

Hefft S, Jonas P (2005) Asynchronous GABA release generates long-lasting inhibition at a hippocampal interneuron-principal neuron synapse. Nat Neurosci 8:1319-1328.

Hefft S, Hulo S, Bertrand D, Muller D (1999) Synaptic transmission at nicotinic acetylcholine receptors in rat hippocampal organotypic cultures and slices. J Physiol 515:769-776.

Heine M, Groc L, Frischknecht R, Béïque J-C, Lounis B, Rumbaugh G, Huganir RL, Cognet L, Choquet D (2008) Surface mobility of postsynaptic AMPARs tunes synaptic transmission. Science 320:201-205.

Horch HL, Sargent PB (1995) Perisynaptic surface distribution of multiple classes of nicotinic acetylcholine receptors on neurons in the chicken ciliary ganglion. J Neurosci 15:7778-7795. 
Iremonger KJ, Bains JS (2007) Integration of asynchronously released quanta prolongs the postsynaptic spike window. J Neurosci 27:66846691.

Irie M, Hata Y, Takeuchi M, Ichtchenko K, Toyoda A, Hirao K, Takai Y, Rosahl TW, Südhof TC (1997) Binding of neuroligins to PSD-95. Science 277:1511-1515.

Ji D, Dani JA (2000) Inhibition and disinhibition of pyramidal neurons by activation of nicotinic receptors on hippocampal interneurons. J Neurophysiol 83:2682-2690.

Jüngling K, Eulenburg V, Moore R, Kemler R, Lessmann V, Gottmann K (2006) $\mathrm{N}$-cadherin transsynaptically regulates short-term plasticity at glutamatergic synapses in embryonic stem cell-derived neurons. J Neurosci 26:6968-6978.

Katz B, Miledi R (1965) The effect of temperature on the synaptic delay at the neuromuscular junction. J Physiol 181:656-670.

Kim E, Sheng M (2004) PDZ domain proteins of synapses. Nat Rev Neurosci 5:771-781.

Kim E, Naisbitt S, Hsueh YP, Rao A, Rothschild A, Craig AM, Sheng M (1997) GKAP, a novel synaptic protein that interacts with the guanylate kinase-like domain of the PSD-95/SAP90 family of channel clustering molecules. J Cell Biol 136:669-678.

Lau PM, Bi GQ (2005) Synaptic mechanisms of persistent reverberatory activity in neuronal networks. Proc Natl Acad Sci U S A 102:1033310338.

Le Magueresse C, Safiulina V, Changeux JP, Cherubini E (2006) Nicotinic modulation of network and synaptic transmission in the immature hippocampus investigated with genetically modified mice. J Physiol 576: 533-546.

Levy RB, Aoki C (2002) Alpha7 nicotinic acetylcholine receptors occur at postsynaptic densities of AMPA receptor-positive and -negative excitatory synapses in rat sensory cortex. J Neurosci 22:5001-5015.

Lu T, Trussell LO (2000) Inhibitory transmission mediated by asynchronous transmitter release. Neuron 26:683-694.

Marrs GS, Theisen CS, Brusés JL (2009) N-Cadherin modulates voltage activated calcium influx via RhoA, p120-catenin, and myosin-actin interaction. Mol Cell Neurosci 40:390-400.

Mauceri D, Gardoni F, Marcello E, Di Luca M (2007) Dual role of CaMKIIdependent SAP97 phosphorylation in mediating trafficking and insertion of NMDA receptor subunit NR2A. J Neurochem 100:1032-1046.

Maximov A, Südhof TC (2005) Autonomous function of synaptotagmin 1 in triggering synchronous release independent of asynchronous release. Neuron 48:547-554.

McCann CM, Tapia JC, Kim H, Coggan JS, Lichtman JW (2008) Rapid and modifiable neurotransmitter receptor dynamics at a neuronal synapse in vivo. Nat Neurosci 11:807-815.

McGehee DS, Heath MJ, Gelber S, Devay P, Role LW (1995) Nicotine enhancement of fast excitatory synaptic transmission in CNS by presynaptic receptors. Science 269:1692-1696.

Naisbitt S, Kim E, Tu JC, Xiao B, Sala C, Valtschanoff J, Weinberg RJ, Worley PF, Sheng M (1999) Shank, a novel family of postsynaptic density proteins that binds to the NMDA receptor/PSD-95/GKAP complex and cortactin. Neuron 23:569-582.

Nakagawa T, Futai K, Lashuel HA, Lo I, Okamoto K, Walz T, Hayashi Y, Sheng M (2004) Quaternary structure, protein dynamics, and synaptic function of SAP97 controlled by L27 domain interactions. Neuron 44:453-467.

Nishi R, Berg DK (1981) Two components from eye tissue that differentially stimulate the growth and development of ciliary ganglion neurons in cell culture. J Neurosci 1:505-513.

Nong Y, Sorenson EM, Chiappinelli VA (1999) Fast excitatory nicotinic transmission in the chick lateral spiriform nucleus. J Neurosci 19: $7804-7811$.

Parker MJ, Zhao S, Bredt DS, Sanes JR, Feng G (2004) PSD93 regulates synaptic stability at neuronal cholinergic synapses. J Neurosci 24:378388.

Piccoli G, Rutishauser U, Brusés JL (2004) N-Cadherin juxtamembrane do- main modulates voltage-gated $\mathrm{Ca}^{2+}$ current via RhoA GTPase and Rhoassociated kinase. J Neurosci 24:10918-10923.

Regalado MP, Terry-Lorenzo RT, Waites CL, Garner CC, Malenka RC (2006) Transsynaptic signaling by postsynaptic synapse-associated protein 97. J Neurosci 26:2343-2357.

Rosenberg MM, Yang F, Giovanni M, Mohn JL, Temburni MK, Jacob MH (2008) Adenomatous polyposis coli plays a key role, in vivo, in coordinating assembly of the neuronal nicotinic postsynaptic complex. Mol Cell Neurosci 38:138-152.

Rosenmund C, Stevens CF (1996) Definition of the readily releasable pool of vesicles at hippocampal synapses. Neuron 16:1197-1207.

Ross BS, Conroy WG (2008) Capabilities of neurexins in the chick ciliary ganglion. Dev Neurobiol 68:409-419.

Rumbaugh G, Sia GM, Garner CC, Huganir RL (2003) Synapse-associated protein-97 isoform-specific regulation of surface AMPA receptors and synaptic function in cultured neurons. J Neurosci 23:4567-4576.

Sans N, Prybylowski K, Petralia RS, Chang K, Wang YX, Racca C, Vicini S, Wenthold RJ (2003) NMDA receptor trafficking through an interaction between PDZ proteins and the exocyst complex. Nat Cell Biol 5:520-530.

Sargent PB (2009) Nicotinic receptors concentrated in the subsynaptic membrane do not contribute significantly to synaptic currents at an embryonic synapse in the chicken ciliary ganglion. J Neurosci 29:3749-3759.

Scheiffele P, Fan J, Choih J, Fetter R, Serafini T (2000) Neuroligin expressed in nonneuronal cells triggers presynaptic development in contacting axons. Cell 101:657-669.

Shimomura A, Ohkuma M, Iizuka-Kogo A, Kohu K, Nomura R, Miyachi E, Akiyama T, Senda T (2007) Requirement of the tumour suppressor APC for the clustering of PSD-95 and AMPA receptors in hippocampal neurons. Eur J Neurosci 26:903-912.

Shoop RD, Martone ME, Yamada N, Ellisman MH, Berg DK (1999) Neuronal acetylcholine receptors with $\alpha 7$ subunits are concentrated on somatic spines for synaptic signaling in embryonic chick ciliary ganglia. J Neurosci 19:692-704.

Shoop RD, Esquenazi E, Yamada N, Ellisman MH, Berg DK (2002) Ultrastructure of a somatic spine mat for nicotinic signaling in neurons. J Neurosci 22:748-756.

Sun J, Pang ZP, Qin D, Fahim AT, Adachi R, Südhof TC (2007) A dual$\mathrm{Ca} 2+$-sensor model for neurotransmitter release in a central synapse. Nature 450:676-682.

Tang L, Hung CP, Schuman EM (1998) A role for the cadherin family of cell adhesion molecules in hippocampal long-term potentiation. Neuron 20:1165-1175.

Temburni MK, Rosenberg MM, Pathak N, McConnell R, Jacob MH (2004) Neuronal nicotinic synapse assembly requires the adenomatous polyposis coli tumor suppressor protein. J Neurosci 24:6776-6784.

Triana-Baltzer GB, Liu Z, Gounko NV, Berg DK (2008) Multiple cell adhesion molecules shaping a complex nicotinic synapse on neurons. Mol Cell Neurosci 39:74-82.

Tu JC, Xiao B, Naisbitt S, Yuan JP, Petralia RS, Brakeman P, Doan A, Aakalu VK, Lanahan AA, Sheng M, Worley PF (1999) Coupling of mGluR/ Homer and PSD-95 complexes by the Shank family of postsynaptic density proteins. Neuron 23:583-592.

Waites CL, Specht CG, Härtel K, Leal-Ortiz S, Genoux D, Li D, Drisdel RC, Jeyifous O, Cheyne JE, Green WN, Montgomery JM, Garner CC (2009) Synaptic SAP97 isoforms regulate AMPA receptor dynamics and access to presynaptic glutamate. J Neurosci 29:4332-4345.

Wyart C, Cocco S, Bourdieu L, Léger JF, Herr C, Chatenay D (2005) Dynamics of excitatory synaptic components in sustained firing at low rates. J Neurophysiol 93:3370-3380.

Zhang ZW, Vijayaraghavan S, Berg DK (1994) Neuronal acetylcholine receptors that bind alpha-bungarotoxin with high affinity function as ligand-gated ion channels. Neuron 12:167-177.

Zhang ZW, Coggan JS, Berg DK (1996) Synaptic currents generated by neuronal acetylcholine receptors sensitive to alpha-bungarotoxin. Neuron 17:1231-1240. 